\title{
HIV/AIDS awareness and related health education needs among slum dwellers of Jodhpur city
} Vibha Joshi ${ }^{1}$, Nitin Kumar Joshi ${ }^{2}$, Komal Bajaj ${ }^{3}$, Pankaj Bhardwaj ${ }^{4}$

${ }^{1}$ Ph.d Scholar, Department of Public health, Maulana Azad University, Jodhpur; ${ }^{2}$ Demonstrator, School of Public Health, All India Institute of Medical Sciences, Jodhpur; ${ }^{3}$ Research Assistant, Sainath hospital \& Research center, Jodhpur; ${ }^{4}$ Additional Professor, Community Medicine \& Family Medicine, Cordiantor, School of Public Health, All India Institute Of Medical Sciences, Jodhpur.

\begin{tabular}{|c|c|c|c|c|c|c|c|}
\hline Abstract & Introduction & Methodology & Results & Conclusion & References & Citation & Tables / Figures \\
\hline \multicolumn{8}{|c|}{ Corresponding Author } \\
\hline \multicolumn{7}{|c|}{$\begin{array}{l}\text { Corresponding Author: Dr. Nitin Kumar Joshi, B110 Krishna Nagar, Jodhpur. } \\
\text { E Mail ID: drjoshinitin30@gmail.com }\end{array}$} & 回粡回 \\
\hline
\end{tabular}

\section{Citation}

Joshi V, Joshi NK, Bajaj K, Bhardwaj P. HIV/AIDS awareness and related health education needs among slum dwellers of Jodhpur city. Indian J Comm Health. 2020;32(1):167-169.

Source of Funding: Nil Conflict of Interest: None declared

\section{Article Cycle}

Received: 14/03/2020; Revision: 21/03/2020; Accepted: 27/03/2020; Published: 31/03/2020

This work is licensed under a Creative Commons Attribution 4.0 International License.

\section{Abstract}

Background: The people living in slums lack the basic civic amenities. Due to deprivation of socioeconomic resources and health care facilities these groups of people are more vulnerable to infectious diseases like HIV/AIDS. Aim\& Objective: To assess the knowledge and awareness about HIV/AIDS and to identify related health education needs in urban slums of Jodhpur. Settings and Design: A cross sectional study was conducted during July - Nov 2018 in slums of Jodhpur city. Methods and Material: Two stage cluster sampling strategy was used to collect data from 1200 participants regarding HIV/ AIDS knowledge and awareness to identify health education needs in urban slums. Statistical analysis used: Descriptive statistics, chi-square test and multivariate logistics analysis were used. Results: A total of 1200 participants were surveyed, out of which $48.5 \%$ were males. Among the study population $58 \%$ ( $n=697$ ) has heard about HIV/AIDS and only $17.5 \%(n=211)$ have knowledge that the HIV and AIDS are different. Only $17.8 \%(n=214)$ have undergone HIV testing. Females were less likely aware about preventive measures of HIV than males $(\mathrm{OR}=0.09,95 \% \mathrm{Cl}=0.05-0.14$, $\mathrm{P}$ value $<0.05)$. The younger population $(15$ 45years) were less likely aware about preventive measures for HIV than older population ( $>45$ years). Only $13.9 \%$ ( $n=110$ ) of tobacco consumers and $11.5 \%(n=78)$ alcohol consumers have undergone HIV testing. Conclusions: The comprehensive health education program should be designed with focus on different education needs according to age and gender of urban slums.

\section{Keywords}

HIV; AIDS; Need Assessment; Poverty Areas

\section{Introduction}

World health organization (WHO) states that there were approximately 37.9 million people living with HIV/AIDS around the globe in 2018. About 770000 HIV-related deaths in 2018 and 1.7 million newly infected cases were accounted(1). In India, as per reports of UNAIDS, 2.1 million were people living with HIV/AIDS in 2017(2). The national adult (15-49 years) HIV /AIDS prevalence in 2017 was estimated to be $0.22 \%(0.16-0.30)$. In 2017, 87.58 thousand people were reported as newly HIV infected while 69.11 thousand deaths due to AIDS-related causes(3).

The rapid growth of urban areas leads to formation of slums due to poor planning and not having enough capacity to meet the needs of rapidly growing population(4). The people living in slums lack the basic civic amenities/ social services like proper utilization of health care, education, sanitation, adequate diet etc. Certain challenges came across in improvement of health for urban poor like lack of identity, low levels of awareness and empowerment and inadequate built environment and policy support for health in slums(5). The lack of socioeconomic resources among urban slums can results in riskier health behaviour, which may further increases the risk of transmission of HIV/AIDS(6). Tobacco, alcohol and other substance abuses are more likely to be reported in slums(5). Researchers suggested that the substance use can reduces the likelihood of using preventive measures like condoms, and also it stimulating the HIV replication(7).

It was reported that in $2011,65.5$ million urban population lives in slum region (i.e. $17.4 \%$ of the urban population of the Indian states) which was increased from $\mathbf{4 2 . 6}$ million in 2001. This may be due to migration of people from rural to urban in search of better jobs and living(8). Due to deprivation of socioeconomic resources and health care facilities in slums, these groups of people are more vulnerable to infectious diseases like HIV/AIDS.

\section{Aims \& Objectives}

1. To assess the knowledge and awareness about HIV/AIDS

2. To identify related health education needs

\section{Material \& Methods}

A cross sectional study was conducted during the period of July -Nov. 2019 among slum population of Jodhpur city. Two stage cluster sampling method was done and data was collected from 1200 participants on knowledge and awareness regarding HIV/AIDS in selected slums. 
Semi-structured questionnaire was used, which comprised of questions on socio-demographics (e.g. age, sex, religion, caste, education, marital status, no. of children, monthly income), respondent's general knowledge towards AIDS/HIV infection (e.g. whether HIV and AIDS are same or not, there is cure or not, coughing and sneezing spread HIV, eating healthy food can keep away from HIV). Descriptive statistics were determined by percentages and numbers and comparisons were between socio-demographic data (e.g. age, gender, occupation, etc.) and awareness about HIV (aware about HIV, HIV and aids are same etc.) was analyzed. Multivariate logistics analysis was done to determine odd ratios and $95 \%$ confidence intervals. To assess the health education needs in urban slum population, the chisquare test of significance was used for analysis whenever it was applicable.

\section{Results}

A total of 1200 participants were surveyed, out of which $48.5 \%$ were males and $51.4 \%$ were females between age group of 15 to 90 years. About $36 \%$ of the study population was illiterate and $47.6 \%$ had education of higher secondary and above. Among the study population $58 \%(n=697)$ has heard about HIV/AIDS and only $17.5 \%(n=211)$ have knowledge that the HIV and AIDS are different. Only $17.8 \%(n=214)$ of the study population have undergone HIV testing. shows socio-demographic profile of study population.

(Table 1) shows odd ratios and 95\% confidence intervals for knowledge regarding HIV/AIDS (difference between HIV and AIDS, Awareness about prevention of HIV, Identification of HIV patient by looking, cure available) to selected sociodemographics characteristics. Knowledge about difference between HIV and AIDS in study population was significantly associated with gender; females had higher odds of not knowing the difference between HIV and AIDS as compared to males (OR= 10. $86,95 \% \mathrm{Cl}=6.90-17.08, \mathrm{P}$ value $<0.05$ ). Females were less likely to be aware about preventive measures of HIV than males $(\mathrm{OR}=0.09,95 \% \mathrm{Cl}=0.05-0.14, \mathrm{P}$ value $<0.05)$. Females had higher odds of misconception in context of identification of HIV patient by looking as compared to males $(\mathrm{OR}=8.69,95 \% \mathrm{Cl}=5.60-13.48, \mathrm{P}$ value $<0.05)$. The younger population $(15-45$ years) were less likely aware about preventive measures for HIV than older population ( $>45$ years).

Among study population $27 \%(n=324)$ stated that HIV spreads through coughing and sneezing, $84 \%(n=1009)$ believe that cure for HIV is available and $84.16 \%(n=1010)$ think that eating healthy food can keep person away from getting HIV. We also surveyed about use of tobacco and alcohol among slum population and found that about $65.7 \%(n=789)$ and $56.5 \%(n=$ 678) were consuming tobacco and alcohol respectively. Around $87 \%(n=689)$ tobacco consumers and 90\% ( $n=610)$ alcohol consumers were having misconception that HIV/AIDS can be prevented by healthy food. Only $13.9 \% \quad(n=110)$ of tobacco consumers and $11.5 \% \quad(n=78)$ alcohol consumers have undergone HIV testing. (Table 2) illustrates knowledge about HIV/AIDS in tobacco and alcohol consumers.

\section{Discussion}

In this study, we analyzed collected data from selected urban slum settlements of Jodhpur to explore the linkages between sociodemographic characteristics and HIV-related knowledge for identifying health education needs.

The overall findings of the study revealed that knowledge and awareness about HIV/AIDS is low in urban slum population.
Similarly, the study conducted in Mumbai showed the presence of knowledge gap about mode of transmission and preventive methods of HIV/AIDS in urban- slums(9). Urban-slum dwellers are relatively poor, vulnerable groups and lack basic health services. Studies suggested that level of knowledge for HIV and use of modern contraception methods is comparatively lower in urban- slums than non-slum population of India(10). These factors put them on more risk of getting HIV infection, so there is need to focus on health education for raising awareness about HIV/AIDS among urban slum population.

The multivariable analysis in study revealed that females have comparatively lower knowledge and awareness regarding HIV/AIDS than males. National AIDS Control Organization reported that in India, around one million females living with HIV/AIDS and suggested the socioeconomic factors that influence vulnerability of females are early marriage, violence and sexual abuse against women(11). Females living in slums usually have low socioeconomic status and limited access to health care services. In the Indian context, women are more at risk of HIV infection in slums due to socio-cultural and economic factors. The women in urban slums have lack of empowerment and deprived of information regarding knowledge and prevention of HIV/AIDS(12). Therefore, it is important to put emphasis on health education strategies specially designed for females of urban slums as they are more vulnerable.

In the study, younger population has low awareness and knowledge regarding preventive methods of HIV infection as compared to older population. This is of major concern as they constitute sexually active group and lack of awareness make them more vulnerable to HIV. Similarly, the study conducted in urban slums of Solapur showed that poor knowledge of preventive measures in adolescent girls exacerbates vulnerability for HIV/AIDS(13). Thus there is a need to formulate HIV prevention heath education strategies which are focused on younger population.

Most of the study population (82\%) has not undergone HIV examination in their lifetime. The probable reason for this could be lack of awareness and reluctance for invasive blood testing. The study conducted in Jodhpur revealed that more number of people preferred for HIV oral testing as compared to routine invasive HIV testing and also suggested rapid oral HIV testing could be more acceptable for HIV screening(14). This emphasizes the need to develop health education strategies for promoting voluntary testing and counseling for HIV

This study also revealed that misconceptions about HIV/AIDS were relatively more in tobacco and alcohol consumers. In India, HIV infected people have higher rates of consuming tobacco and alcohol $(15,16)$. The coexistence of low awareness and substance use among study population can leads to risky sexual behaviour that increases the risk of HIV infection. Sustainable cessation programs for alcohol and tobacco with intensive counselling about HIV/AIDS should be implemented.

\section{Conclusion}

This study necessitates the requirement of effective health education strategies to increase the knowledge and awareness about HIV/AIDS in urban- slums of Jodhpur .

\section{Recommendation}

An effective health education program should be designed with focus on different education needs according to age and gender of urban slums. This study also highlights the need of developing comprehensive IEC package which focus on HIV prevention 
INDIAN JOURNAL OF COMMUNITY HEALTH / VOL 32 / ISSUE NO 01 / JAN - MAR 2020 methods combined with cessation programs for tobacco and alcohol consumers.

\section{References}

1. HIV/AIDS [Internet]. Who.int. 2019 [cited 8 December 2019]. Available from: https://www.who.int/news-room/fact-sheets/detail/hiv-aids

2. India [Internet]. Unaids.org. 2017 [cited 10 December 2019]. Available from: https://www.unaids.org/en/regionscountries/countries/india

3. National AIDS Control Organization \& ICMR-National Institute of Medical Statistics (2018). HIV Estimations 2017: Technical Report. New Delhi: NACO, Ministry of Health and Family Welfare, Government of India. Reyes R., Ahn R., Thurber K., Burke T.F. (2013) Urbanization and Infectious Diseases: General Principles, Historical Perspectives, and Contemporary Challenges. In: Fong I. (eds) Challenges in Infectious Diseases. Emerging Infectious Diseases of the 21st Century. Springer, New York, NY

4. World Health Organization, Regional Office for South-East Asia. ((2011 Addressing health of the urban poor in South-East Asia Region: .challenges and opportunities. WHO Regional Office for South-East Asia

5. Jennings $L$, Mathai $M$, Linnemayr $S$, Trujillo $A$, Mak'anyengo $M$, Montgomery B et al. Economic Context and HIV Vulnerability in Adolescents and Young Adults Living in Urban Slums in Kenya: A Qualitative Analysis Based on Scarcity Theory. AIDS and Behavior. 2017; 21(9):2784-2798.

6. Kapadia F, Vlahov D, Donahoe R, Friedland G. The Role of Substance Abuse in HIV Disease Progression: Reconciling Differences from Laboratory and Epidemiologic Investigations. Clinical Infectious Diseases. 2005; 41(7):1027-1034.
[HIV/AIDS awareness] | Joshi V et al

7. Kumar P. Slums in India: Results from Census, 2011. Journal of Environmental and Social Sciences. 2016; 3(1): 124.

8. Syed S, Gangam S. HIV/AIDS Knowledge and Patterns of sexual behavior among adult slum dwellers in Mumbai, India. International Journal of Medical Research \& Health Sciences. 2015; 4(4):740.

9. Mberu B, Haregu T, Kyobutungi C, Ezeh A. Health and health-related indicators in slum, rural, and urban communities: a comparative analysis. Global Health Action. 2016; 9(1):33163.

10. Women [Internet]. 2016 [cited 6 December 2019]. Available from: https://naco.gov.in/women-0

11. Wadhwa V, Ghosh J, Kalipeni E. Factors affecting the vulnerability of female slum youth to HIV/AIDS in Delhi and Hyderabad, India. GeoJournal. 2010; 77(4):475-488.

12. Wadgave $\mathrm{H}$. Knowledge of HIV/AIDS transmission among the adolescent girls in slum areas. Indian Journal of Sexually Transmitted Diseases and AIDS. 2011; 32(2):139.

13. Joshi V, Joshi NK, Bajaj K. Patient's knowledge about HIV and willingness toward rapid HIV oral testing in dental settings, Jodhpur, Rajasthan. Int J Community Med Public Health 2018; 5:5349-54.

14. Balasundaram, A., Sarkar, S., Hamide, A., \& Lakshminarayanan, S. Socioepidemiologic profile and treatment-seeking behaviour of HIV/AIDS patients in a tertiary-care hospital in south India. Journal of health, population, and nutrition 2014; 32(4):587-594.

15. Kumar R., Swaminathan S. , Flanigan T., Mayer K., Niaura R. HIV \& smoking in India. The Indian journal of medical research 2004; 130: 15 22.

Tables

\begin{tabular}{|c|c|c|c|c|c|c|c|c|}
\hline \multirow{3}{*}{$\begin{array}{l}\text { Variable } \\
\text { Gender }\end{array}$} & \multicolumn{8}{|c|}{ Multivariate logistic regression } \\
\hline & \multicolumn{2}{|c|}{$\begin{array}{l}\text { HIV and AIDS are } \\
\text { same }\end{array}$} & \multicolumn{2}{|c|}{ Awareness about prevention of HIV } & \multicolumn{2}{|c|}{ Identify patient by looking } & \multicolumn{2}{|c|}{ Is HIV/AIDS curable } \\
\hline & OR & $95 \% \mathrm{Cl}$ & OR & $95 \% \mathrm{Cl}$ & OR & $95 \% \mathrm{Cl}$ & OR & $95 \% \mathrm{Cl}$ \\
\hline Female & $\begin{array}{l}10.8 \\
6\end{array}$ & $6.90-17.08$ & 0.09 & $0.05-0.14$ & 8.69 & $5.60-13.48$ & 10.28 & $6.41-16.47$ \\
\hline Male & 1 & reference & 1 & reference & 1 & reference & 1 & reference \\
\hline$P$ value & & $<0.05$ & & $<0.05$ & & $<0.05$ & & $<0.05$ \\
\hline \multicolumn{9}{|c|}{ Educational qualifications } \\
\hline Illiterate & 1.25 & $0.88-1.77$ & 1.04 & $0.73-1.48$ & 1.18 & $0.83-1.67$ & 1.17 & $0.82-1.66$ \\
\hline Primary & 0.92 & $0.56-1.50$ & 1.25 & $0.76-2.04$ & 0.84 & $0.51-1.39$ & 0.64 & $0.37-1.11$ \\
\hline Secondary and above & 1 & reference & 1 & reference & 1 & reference & 1 & reference \\
\hline$P$ value & & $>0.05$ & & $>0.05$ & & $>0.05$ & & $>0.05$ \\
\hline \multicolumn{9}{|l|}{ Age } \\
\hline $15-30$ & 1.93 & $1.19-3.15$ & 0.56 & $0.34-0.94$ & 1.32 & $0.83-2.11$ & 1.07 & $0.68-1.71$ \\
\hline $31-45$ & 1.44 & $0.86-2.41$ & 0.45 & $0.26-0.75$ & 1.09 & $0.66-1.78$ & 0.95 & $0.58-1.55$ \\
\hline 46 and above & 1 & reference & 1 & reference & 1 & reference & 1 & reference \\
\hline$P$ value & & $>0.05$ & & $<0.05$ & & $>0.05$ & & $>0.05$ \\
\hline \multicolumn{9}{|l|}{ Income } \\
\hline Above 20,000 & 1.27 & $0.86-1.87$ & 0.85 & $0.58-1.26$ & 0.79 & $0.53-1.18$ & 0.81 & $0.54-1.21$ \\
\hline $\begin{array}{l}\text { Between 10,000- } \\
20,000\end{array}$ & 0.91 & $0.61-1.37$ & 1.21 & $0.80-1.81$ & 0.87 & $0.58-1.28$ & 0.80 & $0.53-1.20$ \\
\hline Below 10,000 & 1 & reference & 1 & reference & 1 & reference & 1 & reference \\
\hline$P$ value & & $>0.05$ & & $>0.05$ & & $>0.05$ & & $>0.05$ \\
\hline
\end{tabular}

TABLE 2 KNOWLEDGE ABOUT HIV/AIDS IN TOBACCO AND ALCOHOL CONSUMERS

\begin{tabular}{|c|c|c|c|c|c|c|}
\hline \multirow[t]{2}{*}{ Variable } & \multicolumn{3}{|c|}{ Consume tobacco } & \multicolumn{3}{|c|}{ Consume alcohol } \\
\hline & $\begin{array}{l}\text { Frequency } \\
(\mathrm{N}=789)\end{array}$ & $\begin{array}{l}\text { Percentage } \\
\text { (\%) }\end{array}$ & $\begin{array}{l}P \\
\text { value }\end{array}$ & $\begin{array}{l}\text { Frequency } \\
(\mathrm{N}=678)\end{array}$ & $\begin{array}{l}\text { Percentage } \\
\text { (\%) }\end{array}$ & $\begin{array}{l}P \\
\text { value }\end{array}$ \\
\hline HIV/AIDS prevented by eating healthy food & 689 & 87.3 & $<0.05$ & 610 & 89.9 & $<0.05$ \\
\hline Have you ever tested with HIV & 110 & 13.9 & $<0.05$ & 78 & 11.5 & $<0.05$ \\
\hline Information received from any health worker & 194 & 24.5 & $>0.05$ & 164 & 24.1 & $>0.05$ \\
\hline Coughing and sneezing spread HIV & 279 & 35.3 & $<0.05$ & 272 & 40.11 & $<0.05$ \\
\hline HIV spreads through sharing food with others & 493 & 62.4 & $<0.05$ & 497 & 73.3 & $<0.05$ \\
\hline HIV transmitted by mosquito bite & 164 & 20.7 & $<0.05$ & 172 & 25.3 & $<0.05$ \\
\hline
\end{tabular}

